\title{
Mindfulness and problem gambling treatment
}

\author{
Peter Chen ${ }^{1}$, Farah Jindani ${ }^{1}$, Jason Perry ${ }^{2}$ and Nigel L Turner ${ }^{1,3,4^{*}}$
}

\author{
* Correspondence: \\ nigel.turner@camh.ca \\ ${ }^{1}$ Problem Gambling Institute of \\ Ontario, Centre for Addiction and \\ Mental Health, Toronto, Canada \\ ${ }^{3}$ Social Epidemiological Research, \\ Centre for Addiction and Mental \\ Health, Toronto, Canada \\ Full list of author information is \\ available at the end of the article
}

\begin{abstract}
Mindfulness originated from Buddhist contemplative practice 2500 years ago. Mindfulness has increasingly been integrated into a variety of health care programs to address issues such as chronic pain, mental health problems, and addictions. The purpose of this study was to evaluate the feasibility of teaching problem gamblers about mindfulness meditation as part of regular treatment for problem gambling. The study evaluated an 8-week mindfulness group program that included 17 clients from the Problem Gambling Institute of Ontario at the Centre for Addiction and Mental Health (88\% male) using questionnaires that were distributed before the first group session and after the final group session. The evaluation was a mixed method design that included both qualitative and quantitative feedback about the group. All of the participants showed an improvement in their levels of mindfulness after the 8-week treatment program. The Mindfulness Attention Awareness Scale (MAAS) scores increased from a pre-test score of $3.65(S D=1.01)$ to a post-test score of 4.40 $(S D=0.78)$. Qualitative feedback about the group also highlighted a number of improvements in the clients' lives that included being more in control, relaxed and able to stay in the now. The results indicated that mindfulness was successfully taught during the 8-week group program. This study evaluated the suitability of mindfulness as an intervention as part of a problem gambling treatment service. However, the study did not evaluate whether mindfulness improved the clients' ability to resist relapse. Future studies are needed to examine the long-term impact of mindfulness sessions.
\end{abstract}

\section{Background}

The concept of mindfulness originated from Buddhist contemplative practice approximately 2500 years ago. Today, it has been increasingly integrated into a variety of health care programs in order to address issues such as chronic pain (e.g., GardnerNix, 2009; Morone et al. 2008), mental health problems (e.g., Segal et al. 2012), dealing with cancer (e.g., Mackenzie et al. 2007), and addictions (Bowen et al. 2011). Toneatto et al. (2007)) speculated on the role that mindfulness could play in problem gambling recovery. The purpose of the current study was to further this body of research by evaluating whether a mindfulness-based approach could be successfully integrated into the problem gambling treatment service offered by the Problem Gambling Institute of Ontario (PGIO) at the Centre of Addiction and Mental Health (CAMH) in Toronto.

\section{Overview of mindfulness-based approaches}

Marlatt (1985a) was one of the first researchers in the addiction field to recognize the potential for the use of meditation as a coping strategy for individuals who were at risk

(c) 2014 Chen et al.; licensee Springer. This is an open access article distributed under the terms of the Creative Commons Attribution License (http://creativecommons.org/licenses/by/2.0), which permits unrestricted use, distribution, and reproduction in any medium, provided the original work is properly cited. 
for relapse. He suggested that practicing meditation could help in relapse prevention (RP) by providing benefits such as reducing stress and achieving balance in one's life. " $[\mathrm{O}]$ ne of the most significant effects of regular meditation practice is the development of mindfulness - the capacity to observe the ongoing process of experience without at the same time becoming 'attached' or identifying with the content of each thought, feeling, or image. Mindfulness is a particularly effective cognitive skill for the practice of RP. If clients can acquire this ability through the regular practice of meditation, they may be able to 'detach' themselves from the lure of urges, cravings, or cognitive rationalizations that may otherwise lead to a lapse” (p. 319).

Jon Kabat-Zinn (1990) pioneered the implementation of mindfulness in western medicine through the development of his Mindfulness-Based Stress Reduction (MBSR) program. His intent was to treat patients at the University of Massachusetts Medical Centre who suffered from chronic pain and a variety of other medical issues (e.g., living with HIV infection, heart disease, etc.). The focus of mindfulness-based approaches, also called acceptance-based approaches, is on one's relationship to thoughts and emotions. The aim of the MBSR approach is for clients to become aware of and accept, without judgment, their present moment experience and to learn to see thoughts and emotions as passing mental events. Note that the goal is not to change anything about one's experience, but, as defined by Jon Kabat-Zinn (1990), to "pay [ing] attention in a particular way: on purpose, in the present moment, and non-judgmentally" (as cited in Bowen et al., 2011, p.46). In mindfulness practice the client is encouraged to cultivate an attitude of curiosity, openness, friendliness, non-judgmental awareness, and acceptance of one's present moment experience. These attitudes are emphasized through teaching and learning about such themes as non-judging, patience, beginner's mind, trust, non-striving, acceptance and letting go (see Bowen et al., 2011).

Since Kabat-Zinn's initial work, mindfulness-based approaches have been integrated into a variety of other therapies/programs including: Mindfulness-Based Cognitive Therapy (MBCT, see Segal et al. 2002), Mindfulness-Based Relapse Prevention (MBRP, Bowen et al. 2011), Dialectical Behaviour Therapy (DBT, see Linehan, 1993) and Acceptance and Commitment Therapy (ACT, Hayes et al. 1999). A core element of a number of these programs (e.g., MBSR, MBCT, MBRP) is that they all follow an 8 -week group protocol utilizing similar mindfulness meditation practices such as mindful eating, the body scan, sitting meditation (i.e., mindfulness of the breath, body, sounds, thoughts and emotions), mindful walking, and Yoga.

\section{Relation of problem gambling to mindfulness-based approaches}

An important area of problem gambling research involves investigating the cognitive factors that contribute to a gambler's difficulty in controlling the impulse to engage in repeated, persistent gambling (see Petry, 2005; Toneatto, 1999, for reviews). For example, many problem gambling behaviours (e.g., chasing, incremental betting) are the result of erroneous beliefs about the concept of randomness (Toneatto et al., 1997; Turner, 1998; Turner et al. 2006). Yet even if people are taught about the concept of independence of random events, the act of gambling itself can overpower what they have learned (see Benhsain et al. 2004; Sevigny and Ladouceur, 2003). Furthermore, people with gambling problems have reported going into a trance-like state while gambling, 
which suggests that problem gambling often involves automatic thoughts that take place outside of awareness (see Jacobs, 1988; Gupta and Derevensky, 1998).

According to Toneatto et al. (2007), "[d] istinguishing mental events from the responses to them provides a choice to the gambler regarding how best to respond, rather than react, to gambling related cognition. It is argued that improving gambler's mindfulness can help them overcome the erroneous beliefs and automatic behaviours associated with problem gambling. Learning to relate differently to gambling cognitions may be as important as, if not more important than, challenging the specific content of the thoughts" (Toneatto et al., 2007, p. 94).

We believe that if people learn how to be aware of their thoughts by practicing mindfulness techniques, the urges and cravings that often drive a person to gamble, or relapse to gambling, can be overcome. For example, Bowen et al. (2011) uses an "urge surfing" analogy to help clients cope with the intensity of their cravings. Riding the wave of craving (e.g., the urge to gamble) is like riding on a surfboard without being submerged by the intensity of the wave. The idea is that through this meditation exercise, clients become aware of their urges but are not ruled by them. The keys are learning to recognize the impermanence of all experience and understanding urges as passing, mental events that do not have to be acted upon or fought.

In recent years there has been a growing literature on the relationship between mindfulness and problem gambling (see de Lisle et al. 2012; Shonin et al. 2013b). According to de Lisle et al. (2012) the literature indicates that there is an inverse relationship between dispositional mindfulness and psychological distress, and this may be mediated by a number of factors including emotional, cognitive, and behavioural flexibility. For example, Lakey et al. (2007) found a significant negative correlation between gambling problems and mindfulness amongst undergraduate students. In a second study they showed that mindfulness was related to performance on two risk-related judgment and decision-making tasks. Lakey et al. (2007) speculated that "greater attention to and awareness of ongoing internal and external stimuli that characterizes mindfulness may represent an effective means of mitigating the impulsive and addictive responses and intemperate risk-attitudes of individuals with PG" (p. 1708). A 2011 study by de Lisle et al. (as reported in de Lisle et al., 2012) replicated some of these findings with two samples of treatment-seeking problem gamblers. They found that problem gamblers had lower levels of dispositional mindfulness than normative samples of adult community members and university students, and "that dispositional mindfulness was negatively related to gambling urges, gambling pre-occupation, problem gambling severity, gambling expenditure, and gambling frequency" (de Lisle et al., 2012, p. 721).

A study by Riley (2012) examined a type of experiential avoidance called thought suppression and found that thought suppression was positively related to problem gambling, whereas mindfulness was negatively related to problem gambling. De Lisle et al. (2012) reviewed the evidence for a number of different mechanisms that may be involved in mindfulness including dealing with issues such as a myopic focus on reward, psychological distress, rumination, thought suppression, and improving emotional, cognitive, and behavioural flexibility. De Lisle et al. (2012) note that the relationship between "mindfulness and problem gambling behaviour is likely to be very complex" (p. 731) because mindfulness is itself a complex construct. They also discuss a number of theoretical models of how mindfulness may be related to problem gambling. 
Very few studies have evaluated the clinical application of mindfulness for problem gambling. Two case studies have been published that describe the use of mindfulness (see de Lisle et al., 2012), and in both cases, mindfulness was successful in helping the client towards recovery. In addition, two studies have examined the efficacy of Dialectical Behaviour Therapy (DBT) which includes mindfulness as a component of the treatment. Korman et al. (2008) used a DBT model to provide an integrated treatment for problem gambling, anger, and substance abuse. They found that the integrated treatment model reduced substance use, but no measure of specific mindfulness skills were reported. Recently, Christensen et al. (2013) reported an evaluation of the use of a modified DBT approach with treatment-resistant problem gamblers. They found that mindfulness improved significantly from pre-test to post-test.

The current study is an evaluation of a mindfulness group that was run as part of the standard treatment offered at PGIO in Toronto. A mindfulness group was first run in 2010 and incorporated into the standard treatment for clients at PGIO in 2011. The data described in this paper was used to evaluate part of the regular treatment program and not collected as a research project. The study was not a controlled study; the project assessed the extent to which the participants reported improving their levels of mindfulness over the course of the therapy. Because the clients were in an overall treatment program, isolating the part of their recovery resulting from the mindfulness group rather than other components of their treatment (e.g., case management, other groups) was not possible. Therefore outcome data on gambling behaviour was not collected.

This paper reports on the data from three groups that were evaluated in terms of how well they learned to use mindfulness techniques to deal with their gamblingrelated problems. The evaluation used a pre-test and post-test to determine if the participants improved in their level of mindful awareness. In addition, after the 8week course was complete, the participants answered a course reflection questionnaire. We hypothesized that the participants would show a substantial improvement in their mindful awareness of their moment-to-moment experiences.

\section{Methods}

\section{Problem gambling treatment}

Mindfulness awareness groups at the PGIO are run approximately three times per year on an outpatient basis and consist of an 8-week program with 2 hour sessions once a week. Of the groups that were evaluated, 5-13 participants took part. The mindfulness groups are based on the Mindfulness-Based Cognitive Therapy (MBCT) and Mindfulness-Based Relapse Prevention (MBRP) protocols. The group sessions are based on experiential practices, inquiry, and group discussion. Facilitators of the mindfulness groups are therapists at PGIO with personal mindfulness practices.

The Mindfulness Awareness Groups offered clients the opportunity to learn and to practice mindfulness awareness, to understand how mindfulness can be helpful to someone with problems related to gambling, and to enhance coping skills (e.g., relapse 
prevention, impulse control, emotion regulation and stress management). The following is a week by week summary of the content of the groups:

1. Automatic Pilot and Relapse involved learning how to slow down and be more present in one's life through practices such as mindful eating and paying attention to the body.

2. Awareness of Triggers and Craving involved developing greater awareness of triggers to gambling and how to respond from a place of mindful awareness.

3. Mindfulness in Daily Life involved bringing greater mindful awareness to one's daily activities, such as eating, cooking, taking a shower, etc..

4. Mindfulness in High-Risk Situations involved teaching participants how to cope when they are in situations that may put them at risk to gamble.

5. Acceptance and Skillful Action involved the role of acceptance in coping with difficult situations and making skillful choices instead of gambling.

6. Seeing Thoughts as Thoughts involved exploring relationship to experience and how this awareness can be helpful in becoming less overwhelmed when challenged.

7. Self-Care and Lifestyle Balance involved developing greater compassion and kindness toward oneself and others.

8. Social Support and Continuing Practice involved reflecting on the past seven weeks, consolidating the learning and continuing to move forward.

The mindfulness groups were available to problem gambling clients within the treatment agency.

\section{Participants}

In total we ran three Mindfulness Awareness Groups at the PGIO over a period of 2 years. Each group ran separately and was evaluated using the Mindfulness Attention Awareness Scale (MAAS; Brown and Ryan, 2003). Groups 1and 2 each started out with 8 clients, and group 3 started with 11 clients $^{\mathrm{a}}$. A total of 27 participants (93\% male*) completed the pretest questionnaire and attended at least one of the mindfulness group sessions. Participants were over the age of 18 years and were familiar with the treatment philosophy of the PGIO, having completed two prior group treatment programs. The average age of the clients was 52.7 years $(S D=14.8)$. Most of the participants $(80.0 \%)$ had completed high school, and $37.1 \%$ had attended college or university. Approximately one third (31.4\%) of the participants were married or partnered, $22 \%$ were separated, and $42.9 \%$ were single. Just under half (45.7\%) were employed full time; another $22.9 \%$ were retired. Roughly a third (31.4\%) had no comorbid disorder. Comorbidity was assessed either by the client's own psychiatrist or by the staff psychiatrist at PGIO. The most common psychiatric disorder listed in the file was depression (37.1\%), followed by anxiety (14.3\%).

The data were collected between October 2011 and July 2012. Participants were regular clients of the treatment service, attesting to this study being conducted under real world conditions. The program was open to clients who had completed two treatment programs (Preparation for Change and an 8-week Skills for Change group) at PGIO prior to beginning the mindfulness group. Many of the participants were in recovery; thus, their gambling behaviors were stabilized before they began mindfulness group. The exclusion criteria were the same as with any regular group: clients were excluded if actively suicidal or with severe mental health problems that would prevent them from 
participating in a group. The paper presented here is an evaluation of an ongoing treatment program, with data collected as part of the group process and used to improve the therapy. Since no non-treatment procedures were required and no control groups were included, the evaluation did not require ethics approval ${ }^{\mathrm{b}}$.

\section{Outcome measures}

The MAAS was used to assess the participants' level of mindfulness. The scale was used prior to the first treatment session (pre-test) and after the last treatment session (post-test). The scale has 15 items designed to assess a core characteristic of dispositional mindfulness, namely, open or receptive awareness and attention to what is taking place in the present. The scale has strong psychometric properties and has been validated with college, community, and cancer patient samples. Correlational, quasiexperimental, and laboratory studies have shown that the MAAS measures a unique quality of consciousness that is related to, and predictive of, a variety of self-regulation and well-being constructs (see Brown and Ryan, 2003). The measure took roughly 10 minutes to complete.

A Course Reflection Questionnaire was also distributed to the three study groups to obtain anonymous, open-ended feedback regarding what participants thought about the group and what they learned from the group. The following questions were asked:

1. What did you find most valuable about this course? What, if anything, did you learn?

2. What, if anything, has changed for you over the past 8 weeks as a result of your participation?

3. Was there anything that got in the way of your learning or growth or that might have improved the course for you?

4. Other comments?

The course reflection questionnaire also includes 3 course rating scales for feedback that were scored on a scale of 1-10: (1) "On a scale of 1(not at all) to 10 (very), how important has this program been to you?", (2) "On a scale of 1 (not at all) to 10 (very), how likely are you to continue engaging in formal mindfulness practice (e.g. body scan, sitting meditation, mindful stretching/yoga) after this course?" and (3) "On a scale of 1 (not at all) to 10 (very), how likely are you to continue engaging in informal mindfulness practice (e.g., SOBER breathing space, mindful eating, walking, daily activities) after this course?"

\section{Procedure}

For the current study, the group facilitators chose to use the MBRP protocol for a greater focus on relapse prevention into addictive behaviour. Participants completed the MAAS at the beginning and at the end of the 8-week group. At completion of the group, participants also completed a course reflection questionnaire.

The groups were run by Peter Chen and Farah Jindani, both experienced counselors who have received training in mindfulness-based treatment and maintained ongoing 
personal mindfulness practices. Each group was facilitated by either one of the counselors on a rotation basis.

\section{Data analysis}

The project used a mixed-method design that included qualitative and quantitative methods. The scores for the MAAS were computed by adding up the total. The data from the pre-test and the follow up were then analyzed with statistical software SPSS15, using a repeated measures t-test. As an additional analysis, a repeated measures ttest was conducted on each specific item to identify which aspects of mindfulness showed the greatest changes.

The open-ended feedback responses from the Course Reflection Questionnaire were categorized based on their literal content by two of the authors (FJ \& NT) separately, who then combined their results. Grounded theory methodology (Flick 1998; Morone et al., 2008) - a powerful analytic approach whereby the data generates the theory and the researcher approaches the data without any a priori expectations - was used to code the data and identify themes in the experience of the group participants. The feedback responses from all the questionnaires were entered into a single excel spread sheet then coded based on recurring words, phrases, or concepts. New categories were added as needed. The basic categories were then organized into broader themes describing the experience of the participants (Flick 1998).

Feedback sheets were collected anonymously, allowing participants to freely express their opinions and to protect against response bias. To prevent researcher bias, two of the authors examined the results separately and then collaborated on the coding, one of whom (NT) was not connected with the groups and thus had no vested interest in the outcome of the analysis. Once identified, the codes were reviewed and verified by a third researcher, the lead author on the paper.

\section{Results}

Group 1 started out with 8 clients and finished with 5, group 2 started with 8 clients and finished with 7, and group 3 started with 11 clients and finished with 6 . The overall retention rate was $63 \%$ (17 out of 27). Of the 17 who completed all 8 sessions, $88 \%$ were male.

Table 1 presents the internal reliability analysis of the measure. The Cronbach alpha for the MAAS scale was .93 for the pre-test and .96 for the post-test. All items had substantial correlations with the total score and the Cronbach's Alpha if deleted did not indicate any item that should be deleted. Based on these results, the MAAS has strong internal reliability.

For the 17 clients who completed the group sessions, average pre-treatment score on the MAAS was $3.65(S D=1.01)$ and post treatment score on the MAAS was 4.40 $(S D=0.78)$. This difference was significant, $t(16)=4.9, p<.001$. The average change in scores was $0.75(S D=.63)$ for a Cohen's d of 1.18 , indicating a large effect size. In fact, a close examination of the data revealed that all of the participants had a higher score on the post-test than on the pre-test. We also conducted an intent-to-treat analysis in which the pre-treatment scores were substituted for missing post-treatment scores for those clients who did not provide post-treatment scores. This method corrects for the bias that can occur when only successful clients are measured at follow-up. For the 27 


\begin{tabular}{lcc}
\hline Item & Cronbach's Alpha & Alpha if item deleted \\
\hline 1 & 0.31 & 0.93 \\
2 & 0.73 & 0.92 \\
3 & 0.58 & 0.93 \\
4 & 0.60 & 0.93 \\
5 & 0.56 & 0.93 \\
6 & 0.60 & 0.93 \\
7 & 0.76 & 0.92 \\
8 & 0.78 & 0.92 \\
9 & 0.87 & 0.92 \\
10 & 0.78 & 0.92 \\
11 & 0.75 & 0.92 \\
12 & 0.63 & 0.93 \\
13 & 0.67 & 0.93 \\
14 & 0.90 & 0.92 \\
15 & 0.47 & 0.93 \\
\hline
\end{tabular}

clients in the intent-to-treat analysis, the average pre-treatment score on the MAAS was $3.62(S D=1.00)$ and post-treatment score on the MAAS was $4.09(S D=0.96)$. This difference was significant, $t(26)=4.01, p<.001$. The average change in scores was 0.47 $(S D=0.62)$ for a Cohen's d of 0.76, indicating a moderately large effect size.

We also examined the results for males and females. The males increased their score on the MAAS from $3.62(S D=1.06)$ to $4.28(S D=0.70)$; the females increased their score from $3.63(S D=0.90)$ to $5.37(S D=.90)$. Given that there were only 2 female participants, a statistical comparison of the results by gender was not possible.

We also looked at the Ms and SDs for each of the MAAS items (see Table 2). The lowest overall pre-test scores were Items 5 ("I tend not to notice feelings of physical tension or discomfort until they really grab my attention") and 6 ("I forget a person's name almost as soon as I've been told it for the first time"). Of the 15 items on the MAAS, all showed an increase in scores from pre-treatment to post-treatment. In each case, this meant that the participants endorsed engaging in the behavior less often, which indicates that they have become more mindful. Eleven of the items showed significant increases in scores with the largest increases being for Items 5 ("I tend not to notice feelings of physical tension or discomfort until they really grab my attention"), 13 ("I find myself preoccupied with the future or the past"), and 4 ("I tend to walk quickly to get where I'm going without paying attention to what I experience along the way"). The smallest improvements were for Items 15 ("I snack without being aware that I'm eating"), 2 ("I break or spill things because of carelessness, not paying attention, or thinking of something else") and 12 ("I drive places on 'automatic pilot' and then wonder why I went there").

\section{Course reflection questionnaire results}

The results of the open-ended feedback questions $(\mathrm{N}=17)$, shown in Table 3, were also very promising. Participant responses were organized into seven themes, six of which 
Table 2 Pre-test and Post-test means and standard deviations for each of the $\mathbf{1 5}$ items on the MAAS

\begin{tabular}{|c|c|c|c|c|c|c|}
\hline \multirow[b]{2}{*}{ Item \# } & \multirow[b]{2}{*}{ Item content } & \multicolumn{2}{|c|}{ Pre-test } & \multicolumn{2}{|c|}{ Post-test } & \\
\hline & & $M$ & $S D$ & $M$ & $S D$ & \\
\hline 1 & $\begin{array}{l}\text { I could be experiencing some emotion and not be } \\
\text { conscious of it until sometime later. }\end{array}$ & 3.71 & 1.05 & 4.53 & 0.87 & *** \\
\hline 2 & $\begin{array}{l}\text { I break or spill things because of carelessness, not } \\
\text { paying attention, or thinking of something else. }\end{array}$ & 4.88 & 1.27 & 5.29 & 1.10 & \\
\hline 3 & $\begin{array}{l}\text { I find it difficult to stay focused on what's } \\
\text { happening in the present. }\end{array}$ & 3.88 & 1.41 & 4.71 & 1.10 & $* *$ \\
\hline 4 & $\begin{array}{l}\text { I tend to walk quickly to get where I'm going without } \\
\text { paying attention to what I experience along the way. }\end{array}$ & 3.24 & 1.48 & 4.29 & 0.85 & $* *$ \\
\hline 5 & $\begin{array}{l}\text { I tend not to notice feelings of physical tension or } \\
\text { discomfort until they really grab my attention. }\end{array}$ & 3.00 & 1.15 & 4.24 & 1.03 & $* * *$ \\
\hline 6 & $\begin{array}{l}\text { I forget a person's name almost as soon as I've been } \\
\text { told it for the first time. }\end{array}$ & 2.76 & 1.52 & 3.53 & 1.37 & $* * *$ \\
\hline 7 & $\begin{array}{l}\text { It seems I am "running on automatic", without much } \\
\text { awareness of what I'm doing. }\end{array}$ & 3.59 & 1.18 & 4.18 & 1.24 & * \\
\hline 8 & $\begin{array}{l}\text { I rush through activities without being really } \\
\text { attentive to them. }\end{array}$ & 3.41 & 1.37 & 4.29 & 1.05 & $* *$ \\
\hline 9 & $\begin{array}{l}\text { I get so focused on the goal I want to achieve that I } \\
\text { lose touch with what I'm doing right now to get there. }\end{array}$ & 3.53 & 1.46 & 4.18 & 1.19 & * \\
\hline 10 & $\begin{array}{l}\text { I do jobs or tasks automatically, without being aware } \\
\text { of what I'm doing. }\end{array}$ & 3.59 & 1.28 & 4.35 & 1.06 & * \\
\hline 11 & $\begin{array}{l}\text { I find myself listening to someone with one ear, doing } \\
\text { something else at the same time. }\end{array}$ & 3.29 & 0.92 & 4.24 & 0.97 & $* * *$ \\
\hline 12 & $\begin{array}{l}\text { I drive places on "automatic pilot" and then wonder } \\
\text { why I went there. }\end{array}$ & 4.24 & 1.30 & 4.71 & 1.05 & \\
\hline 13 & I find myself preoccupied with the future or the past. & 3.12 & 1.50 & 4.29 & 1.16 & $* * *$ \\
\hline 14 & I find myself doing things without paying attention. & 3.88 & 1.27 & 4.47 & 1.07 & \\
\hline 15 & I snack without being aware that I'm eating. & 4.53 & 1.28 & 4.76 & 1.03 & \\
\hline
\end{tabular}

made references to positive lifestyle changes (from most noted to least noted): (1) use of mindfulness techniques; (2) increased awareness of triggers and ability to cope; (3) feeling calmer, more relaxed and more patient; (4) improved self-discipline, control, or control over gambling; (5) better interpersonal skills, (6) positive experiences in their lives, and (7) barriers to mindfulness.

\section{Use of mindfulness techniques}

The most frequently noted responses relate directly to the mindfulness techniques that participants had learned during the classes and comprise the first theme: staying in the present moment, being aware, breathing, and separating from thoughts. Participants particularly noted "learning to be in the present moment" and "taking things one step at a time". Participants learned to "stay on NOW, in this moment" when the mind was "very busy". They reported being more aware of the activities that they engage in on a daily basis and using this enhanced self-awareness to separate themselves from their thoughts. In this way individuals are able to accept their thoughts without being controlled by them; impulses to gamble, for example, could be experienced but would not overwhelm. This concept is directly related to another key belief in mindfulness- 
Table 3 Themes, subthemes, and sample quotes from the course reflections questionnaire

\begin{tabular}{|c|c|}
\hline Theme/sub-theme & Example \\
\hline \multicolumn{2}{|l|}{ (1) Mindfulness techniques: } \\
\hline Non-judgemental detachment & $\begin{array}{l}\text { Now I can recognize what [s] happening internally and separate } \\
\text { myself from what I'm thinking. }\end{array}$ \\
\hline SOBER (Bowen et al., 2011) & How important it is to breathe and slow down (SOBER). \\
\hline Staying in the moment & $\begin{array}{l}\text { My brain is very busy but in this course, I learned how to } \\
\text { stay on NOW, in this moment. }\end{array}$ \\
\hline Aware of the moment & $\begin{array}{l}\text { I have become more aware of the present moment. I have } \\
\text { become more mindful and conscious about the present moment, } \\
\text { learning to take things one step at a time. }\end{array}$ \\
\hline \multicolumn{2}{|c|}{ (2) Increased awareness of triggers and ability to cope } \\
\hline \multirow[t]{2}{*}{ Aware of triggers } & To become more aware of life situations and how to deal with them. \\
\hline & $\begin{array}{l}\text { Mindfulness/awareness of warning signs and triggers is my } \\
\text { main tool to not returning to coping via gambling. }\end{array}$ \\
\hline Able to deal with life situations & $\begin{array}{l}\text { I had a bit of a crisis while I took this course and it got me through } \\
\text { by practicing mindfulness and journaling. }\end{array}$ \\
\hline \multicolumn{2}{|c|}{ (3) Feeling calmer, more relaxed and more patient } \\
\hline \multirow[t]{2}{*}{ Patient and calm } & Learn how to calm down by using the 3 minute breathing meditation. \\
\hline & I have more patience and am aware of my heartbeat. \\
\hline Taking time on a task & Learnt about taking your time on something without stressing yourself. \\
\hline Less anxiety & Learn how to calm down - Less anxiety. \\
\hline
\end{tabular}

(4) Improved self-discipline, control, or control over gambling:

\begin{tabular}{|c|c|}
\hline \multirow[t]{2}{*}{ Self-discipline } & Stop and think before I do any harm or damage to myself. \\
\hline & I learned to discipline myself better. \\
\hline Avoid auto pilot & To be able to control going into auto pilot. \\
\hline \multicolumn{2}{|c|}{ (5) Better interpersonal skills } \\
\hline Improved relationships & Learn not to judge people so fast. \\
\hline Better at listening & $\begin{array}{l}\text { Much better listener and not affected by small things. } \\
\text { Conflicts are less severe when you don't react right away. }\end{array}$ \\
\hline \multicolumn{2}{|c|}{ (6) Positive experiences in their lives } \\
\hline & Learned how I sometimes get rid of bad thinking and be relaxed. \\
\hline & Helping with my job/career. \\
\hline & Become a better person. \\
\hline & Mental and physical health has improved greatly. \\
\hline & Always brightened my mood. \\
\hline & Feel more positive. \\
\hline \multicolumn{2}{|c|}{ (7) Barriers to meditation } \\
\hline & I found the amount of time suggested for homework not realistic \\
\hline & Time is always a barrier. \\
\hline
\end{tabular}

achieving a non-judgmental awareness of one's thoughts. Participants also related that they had learned the importance of breathing and slowing down using the SOBER method (Stop, Observe, Breathe, Expand \& Respond; Bowen et al., 2011) to keep themselves in the present moment. In total, six individuals mentioned the SOBER method in their responses to the questionnaire. These responses indicate that the participants had learned various mindfulness techniques from their sessions, were applying them in their lives and finding them useful. 
Increased awareness of triggers and ability to cope

The second most common type of response that participants found the lessons valuable in learning about triggers to negative behaviour, preparing for stressors in their lives, and finding ways to improve their ability to cope. A key consideration for any addiction recovery-and especially important for relapse prevention-includes equipping clients with coping strategies for situations that lead to distress (Marlatt, 1985b). Our participants reported that they have become more aware of challenging life situations and have a better understanding of how to deal with them. As a result of being part of the group, participants have become less reactive to their triggers and are no longer overwhelmed. This enhanced awareness has made it possible to cope with issues in their lives. One person noted that using mindfulness and journaling helped with managing a particular crisis situation that occurred during the 8-week course. Another person noted that mindfulness is now a main tool for resisting the urge to gamble. These responses in this second theme indicate that the participants have learned the mindfulness techniques offered in the group and are actively using them to deal with the triggers that would normally have led them to relapse.

\section{Feeling calmer, more relaxed and more patient}

The third most common response was that participants felt calmer, more relaxed and more patient. For example, one person reported having the patience to take their time completing a task without being overcome by stress. One person specifically noted that s/he had "learned how to calm down by using the 3-minute breathing meditation". Several people noted that they have become more patient and non-judgmental as a result of the mindfulness group. One person noted that $\mathrm{s} /$ he was aware of her/his heartbeat. Closely related to patience, a few people noted that they were able to be less anxious. These responses indicate that the participants have learned to use the mindfulness techniques offered in the group to feel calmer, more relaxed, and more patient.

\section{Improved self-discipline, self-control, or control over gambling}

The fourth theme involves improved self-discipline, self-control, or control over gambling. Self-control refers to clients developing an ability to control their own behaviour (Mackenzie et al., 2007). A number of individuals in our study reported that mindfulness helped them stop and think about what they were doing, which made it possible to reset their "mind (s) and allowed a rational response to life events". Others noted that through mindfulness they had learned self discipline. One participant recounted that s/he could now prevent "going into autopilot", an important development as problem gamblers often report being on autopilot while gambling (Gupta and Derevensky, 1998). Another participant noted having achieved a much greater understanding of the mind and body ("10 fold") and therefore was able to have more control over every aspect of his or her life. Having achieved self-control, one participant noted that the technique not only helped limit the inclination to gamble, but also, more importantly, was a positive career influence. These responses indicate that the participants learned to use the mindfulness techniques offered in the group to improve their self-control and, in particular, their control over their gambling. 


\section{Better interpersonal skills}

The fifth theme to be established involves improvements in participants' abilities to relate to other people and to be compassionate. People with addiction problems often have difficulties with interpersonal relationships, and the resulting conflicts often lead to relapse (Marlatt, 1985b; Turner et al. 1997; Turner et al. 2013). A number of participants in our study responded that they had achieved a better understanding of social relationships. Others noted that they had learned not to judge people so quickly. Two people reported being better listeners, one of whom also noted that by using mindfulness techniques, s/he was less reactive, which in turn reduced conflicts. Another participant explained that close friends and family had noticed a positive change in his/her ability to listen. These responses indicate that learning the mindfulness techniques improved participants' understanding of and their ability to interact with other people. This finding is significant because it shows that mindfulness may help reduce interpersonal conflict, which can be a major stressor and trigger for people in early recovery.

\section{Positive experiences in their lives}

The sixth theme can be summed up as positive impacts on the individual beyond meditation itself. Responses from participants included "feeling better" about themselves, "clearer thinking", "helping with a job or career", "becoming a better person", and "improving mental and physical health". This feedback points to mindfulness as having a profound effect on the participants' well-being beyond the scope of the mindfulness exercises themselves. By learning and applying a variety of techniques, participants had improved their lives.

\section{Barriers to mindfulness}

As a seventh theme we have grouped together a small number of comments that reflect what participants see as barriers to mindfulness. In total there were five such comments on the evaluation sheets. One person wished the "course was longer". Three people noted that lack of time was a barrier to engaging in meditation, especially finding time to do the homework. One person was "disturbed by another individual in the group" but did not know why. Overall, few people had comments reflecting barriers to mindfulness, but we note that these feedback sheets were distributed after the final group session and so were completed by those who had stayed for the duration of the program. Individuals who did not stay in the group may have provided additional comments under this theme.

\section{Course ratings}

We examined the feedback ratings from the participants. On average, participants rated the program very highly. On a scale of 1 to 10 , the average score for the first rating question: "How important has this program been to you?" was $8.6(S D=1.3)$, indicating that the majority of the participants found the program very important. For the second rating question: "Do you plan to continue to formally practice mindfulness?" the average score was $8.7(S D=1.5)$, indicating that the majority of those people who rated the program planned to formally continue this practice (e.g. body scan, sitting meditation, mindful stretching/yoga). For the third question: "Do you plan to continue to 
informally practice mindfulness?" the average rating was $8.9(S D=1.5)$, indicating that the majority of the participants planned to continue to engage in mindfulness on an informal basis (e.g., SOBER breathing space, mindful eating, walking, daily activities, etc.).

\section{Discussion}

One active area of clinical research involves integrating the concept of mindfulness (originally a Buddhist contemplative practice) into a variety of health care programs (see Toneatto, 2002 for a discussion of some possible applications). The goal of the current study was to extend this research to problem gambling (see Toneatto et al., 2007) by evaluating whether a mindfulness-based approach could be successfully integrated into the problem gambling treatment service offered by the Problem Gambling Institute of Ontario in Toronto. This study evaluated the use of mindfulness techniques in a group-based setting to determine the suitability of mindfulness training as part of a standard problem gambling treatment service. The self-report data of the participants are promising, and the results warrant assessment by means of more rigorous, empirical study.

\section{Summary of research findings}

In our study, clients joined in an 8-week mindfulness group in which they completed a MAAS at the beginning (pre-test) and at the end (post-test) of treatment, along with a Course Reflection Questionnaire. The key result was that there was a statistically significant improvement in the levels of mindfulness of participants as a result of taking part in these groups (as indicated by the MAAS).

The responses from the Course Reflection Questionnaire corroborated the results from the MAAS. Seven themes emerged from the feedback, six of which relate to improvements in their lives: participants (1) indicated that were using the mindfulness techniques they had learned, such as SOBER and staying in the now; (2) noted an increased awareness of the triggers to negative behaviour and an increased ability to cope with stress; (3) felt calmer, more relaxed, and more patient. (4) developed better selfdiscipline, control, or control over gambling as a result of mindfulness; (5) reflected that mindfulness techniques had improved their interpersonal skills including their ability to listen to other people; and (6) related that they had more positive experiences in their lives The seventh theme to emerge from the feedback concerned what participants perceive to be barriers to meditation. Overall, these responses indicated that the clients who took part in the groups have learned to use the mindfulness techniques to improve their ability to cope, their self-control, their ability to calm down, and their control over their gambling.

Some of the themes we noted above have also been found in previous qualitative studies of mindfulness. The first theme of learning and using the techniques of mindfulness meditation is similar to the "Opening to change" reported by Mackenzie et al. (2007) and the "Processes of meditation" reported by Morone et al. (2008). The second theme regarding awareness of triggers which improved participants' ability to cope with stressors is similar to the first theme reported by Morone et al. (2008) whereby clients use mindfulness to cope with pain, and the sub-theme of "Developing emotion-focused coping strategies" noted by Morone et al. (2008). Our third theme of being more 
relaxed is similar to the "Improved sleep" noted by Morone et al. (2008). Self-control, our fourth theme, was also noted in Mackenzie et al. (2007). The fifth theme of improving participants' interpersonal relationships was also reported as "Interactions with others" by Shonin et al. (2013a). The sixth theme-mindfulness provided an overall improvement in participants' lives-is related to the theme of "Personal growth" noted by Mackenzie et al. (2007) and the theme "Achieving well-being" noted by Morone et al. (2008). Barriers to meditation were also identified as a theme by Morone et al. (2008). These findings show a degree of commonality between the current study and previous qualitative studies of mindfulness and provide some validation of the structure found in the present study. However, unlike Mackenzie et al. (2007), in the current study, no one noted "Shared experience" or "Spirituality" as a particular benefit of the meditation. The lack of any comment on shared experience may be because our clients had participated in previous group therapy programs, were already familiar with group therapy and therefore sharing was not a novel experience. Other differences among the studies, such as spirituality, may be related to the (e.g., cancer vs. gambling) reason for being in group therapy (e.g., coping with cancer vs. recovering from a gambling problem) and also to the difference in data collection methods (e.g., interview vs. feedback questionnaire).

We believe that taking part in the 8-week program is only the beginning of a shift in the way that participants relate to their thoughts and feelings, and that much work is needed for further growth. The data from the rating scales indicated that the mindfulness group was well-liked by participants and that they plan to continue practicing mindfulness in their lives. Overall, the program helped meet the needs of participants and provided them with concrete tools for self-control and relaxation, and thus our results show that mindfulness was successfully integrated into the problem gambling treatment service offered by the PGIO at CAMH.

\section{Implications of Our study for problem gambling}

Our study extends previous research by Kabat-Zinn (1990) who pioneered the implementation of mindfulness in western medicine, and, more recently, Toneatto et al. (2007) who speculated on the role of mindfulness in problem gambling. According to Shonin et al. (2013b) and de Lisle et al. (2012), little research has been conducted on the use of mindfulness for problem gambling treatment. As noted above, there have been two case studies published about mindfulness (see, de Lisle et al., 2011) and two research studies that evaluated DBT (Korman et al., 2008; Christensen et al., 2013). The study by Christensen et al. (2013) reported that the intervention resulted in significant improvements in the participants' level of dispositional mindfulness. In general, there has been relatively little published research on the use of mindfulness for problem gamblers.

Shonin et al. (2013b) list a number of factors that have contributed to the shortage of mindfulness programming, including a lack of trained therapists and treatment services for problem gambling in the United Kingdom. In Canada, problem gambling treatment is widely available through the public health care system, and two of the therapists at PGIO are experienced facilitators in mindfulness approaches.

People with gambling problems often engage in negative behaviour to deal with anxiety, tension, and other stress-related feelings (see Jacobs, 1988; Turner, Jain, Spence 
and Zangeneh 2008; Turner et al., 2006). One common reason for relapse into addictive behavior is physical and emotional pressures (see Marlatt, 1985b; Turner et al. 1997). A number of the participants in our program noted that practicing mindfulness techniques has helped them cope with stress, while other participants revealed that mindfulness had allowed them to relax. According to Kabat-Zinn (1990), meditation can reduce stress in one's life and is often recommended by medical doctors for the treatment of hypertension. Although relaxation and stress reduction are common byproducts of mindfulness practice, the core skill in mindfulness is not relaxation/stress reduction but learning to be with one's experience, regardless of what is happening in any given moment. Mindfulness is about learning to turn towards one's experience rather than away from it. For example, when clients are experiencing the urge to gamble, instead of avoiding or distracting themselves from their experience, they are taught to face the impulse yet remain relaxed and detached (see Bowen et al., 2011; Toneatto et al., 2007). The qualitative results from the current study suggest that mindfulness meditation can be a helpful coping strategy for problem gamblers.

Mindfulness is more than just a relaxation technique. Lakey et al. (2007) have argued that greater awareness of and attention to internal and external stimuli may help mitigate the impulsive and addictive responses. Essentially they view mindfulness as a self-regulatory capacity that can "help lessen the grip of automatic thoughts, affective reactions, and behaviour patterns" (p. 1708). Responses by a number of the participants in the groups noted that mindfulness had allowed them to be aware of, and therefore gain control over, their impulses (e.g., not "going into autopilot").

\section{Limitations}

The current study employed a small sample and did not use a control group. We relied largely on self-reports, which may be seen as a limitation, but these anecdotes provide the first step towards a more systematic study. Furthermore, we believe our study's advantage is that data were collected from an actual regular treatment sample, not from a research sample, and as such, can be generalizable to other treatment samples. The data collected provides only a short-term evaluation of the mindfulness levels of the participants; no attempts were made to assess the long-term impact of these sessions, nor were any attempts made to determine if the participants' gambling behavior changed as a result of practicing mindfulness. During the course of the study most of the participants were already in recovery, and changes in gambling were not expected. However, given that one of the purposes of the group was to facilitate relapse prevention, a long-term follow-up of gambling behavior could be used to determine if this treatment program prevents relapse. The retention rate in the program was $63 \%$ which is comparable with other similar groups. We do not know why some people dropped out. It could be that they did not find the group helpful or that they were not ready for the group, or that they might have had a schedule conflict. It is important to keep in mind that the result may be biased in some unknown way by the dropouts.

\section{Conclusions}

We believe that the application of mindfulness-based relapse prevention to problem gambling is particularly relevant because of the large role that erroneous beliefs play in 
problem gambling (e.g., Toneatto, et al., 1997; Turner, et al., 2006) and the tendency of people who have problems with gambling to engage in automatic thoughts while gambling (e.g., Benhsain et al., 2004; Jacobs, 1988; Gupta and Derevensky, 1998). Our notion is that becoming aware of these automatic thoughts should improve a gambler's ability to resist his or her urge to gamble. The results of the current study indicate that our treatment program was successful at teaching people with gambling problems how to engage in mindfulness awareness practice. The scores from both the MAAS scale and the responses from the qualitative feedback sheets show that the mindfulness program was successfully implemented in a group setting. Further study is needed to determine how effective this program is in terms of improving the outcome for treatment and reducing relapse. In addition, Shonin et al. (2013b) have also noted that other aspects of Buddhist-derived interventions may also be of benefit to individuals with addictions. These techniques may open up other potential avenues for research and treatment for the problem gambler.

\section{Endnotes}

${ }^{\mathrm{a}}$ In addition there were three participants in the group who were family members of problem gamblers, and one person who had a process addiction other than gambling. Their data were not included in the paper.

${ }^{\mathrm{b}}$ The data were collected as part of the group process. Since no non-treatment procedures were required and the study did not include any control group, the evaluation did not require ethics approval. According to the Tri council policy Article 2.5, because the project was pure evaluation, an ethics review was not required. http://www.ethics. gc.ca/pdf/eng/tcps2/TCPS_2_FINAL_Web.pdf. We checked with the Chair of the Research Ethics board who agreed that the project did not require an ethic's review.

Competing interests

The authors have declared no competing interests.

Authors' contributions

PC \& FJ developed the program and conducted the groups. PC wrote the first draft of the manuscript. JP helped in writing and revising the paper, addressing the reviewer's comments, and interpreting the broader application of the issues. NT and JP conducted and interpreted the statistical analysis of the data. FJ \& NT did the qualitative sorting of the open ended responses. NT, PC, JP, \& FJ all participated in revising and editing the final version of the paper.

All authors read and approved the final manuscript.

\section{Author details}

${ }^{1}$ Problem Gambling Institute of Ontario, Centre for Addiction and Mental Health, Toronto, Canada. ${ }^{2}$ Department of Psychology, University of Western Ontario, 1151 Richmond St, London, ONN6A 3K7Canada. ${ }^{3}$ Social Epidemiological Research, Centre for Addiction and Mental Health, Toronto, Canada. ${ }^{4}$ Department of Public Health, University of Toronto, Toronto, Canada.

Received: 19 April 2013 Accepted: 17 December 2013

Published: 12 February 2014

\section{References}

Benhsain, K, Taillefer, A, \& Ladouceur, R. (2004). Awareness of independence of events and erroneous perceptions while gambling. Addictive Behaviors, 29, 399-404.

Bowen, S, Chawla, N, \& Marlatt, GA. (2011). Mindfulness-based relapse prevention for addictive behaviors. A clinician's guide. New York: Guilford.

Brown, KW, \& Ryan, RM. (2003). The benefits of being present: mindfulness and its role in psychological well-being. Journal of Personality and Social Psychology, 84, 822-848.

Christensen, DR, Dowling, NA, Jackson, AC, Brown, M, Russo, J, Francis, K, \& Umemoto, A. (2013). A pilot of an abridged Dialectical Behavior Therapy program as a treatment for problem gambling. Behaviour Change, 20(2), 117-137.

de Lisle, SM, Dowling, NA, \& Allen, JS. (2011). Mindfulness-based cognitive therapy for problem gambling. Clinical Case Studies, 10, 210-228.

de Lisle, SM, Dowling, NA, \& Allen, JS. (2012). Mindfulness and problem gambling: a review of the literature. Journal of Gambling Studies, doi:10.1007/s10899-011-9284-7. 
Flick, U. (1998). An introduction to qualitative research. London, UK: Sage publications.

Gardner-Nix, J. (2009). The mindfulness solution to pain: step-by-step techniques for chronic pain management. Oakland, CA: New Harbinger Publications, Inc

Gupta, R, \& Derevensky, JL. (1998). An empirical examination of Jacobs' general theory of addictions: Do adolescent gamblers fit the theory? Journal of Gambling Studies, 14(1), 17-50.

Hayes, SC, Strosahl, KD, \& Wilson, KG. (1999). Acceptance and commitment therapy. An experiential approach to behaviour change. New York: Guilford.

Jacobs, DF. (1988). Evidence for a common dissociative-like reaction among addicts. Journal of Gambling Behavior, 4, 27-37.

Kabat-Zinn, J. (1990). Full catastrophe living: using the wisdom of your body and mind to face stress, pain, and illness. New York: Delacorte.

Korman, L, Collins, J, Littman-Sharp, N, Skinner, W, McMain, S, \& Mercado, V. (2008). Randomized control trial of an integrated therapy for comorbid anger and gambling. Psychotherapy Research, 18(4), 454-465.

Lakey, CE, Campbell, KW, Brown, KW, \& Goodie, AS. (2007). Dispositional mindfulness as a predictor of the severity of gambling outcomes. Personality and Individual Differences, 43(2007), 1698-1710.

Linehan, MM. (1993). Cognitive-behavioral treatment of borderline personality disorder. New York: Guilford.

Mackenzie, MJ, Carlson, LE, Munoz, M, \& Speca, M. (2007). A qualitative study of self-perceived effects of mindfulness-based stress reduction (MBSR) in a psychosocial oncology setting. Stress and Health, 23, 59-69.

Marlatt, GA. (1985a). Lifestyle modification. In GA Marlatt \& JR Gordon (Eds.), Relapse prevention: maintenance strategies in the treatment of addictive behaviours (pp. 280-349). New York: Guilford.

Marlatt, GA. (1985b). Situation determinants of relapse and skill-training interventions. In GA Marlatt \& JR Gordon (Eds.), Relapse prevention: maintenance strategies in the treatment of addictive behaviours (pp. 71-126). New York: Guilford.

Morone, NE, Lynch, CS, Greco, CM, Tindle, HA, \& Weiner, DK. (2008). "I felt like a new person". The effects of mindfulness meditation on older adults with chronic pain: Qualitative narrative analysis of diary entries. Journal of Pain, 9, 841-848.

Petry, NM. (2005). Pathological gambling: etiology, comorbidity and treatment. Washington, DC: American Psychological Association.

Riley, B. (2012). Experiential avoidance mediates the association between thought suppression and mindfulness with problem gambling. Journal of Gambling Studies, doi:10.1007/s10899-012-9342-9.

Segal, Z, Williams, JMG, \& Teasdale, J. (2002). Mindfulness-based cognitive therapy for depression. New York: Guilford.

Segal, ZV, Williams, JMG, \& Teasdale, JD. (2012). Mindfulness-based cognitive therapy for depression: a New approach to preventing relapse (2nd ed.). New York: Guilford.

Sevigny, S, \& Ladouceur, R. (2003). Gamblers' irrational thinking about chance events: The 'double switching' concept. International Gambling Studies, 3, 163-170.

Shonin, E, Van Gordon, W, \& Griffiths, MD. (2013a). Meditation Awareness Training (MAT) for improved psychological wellbeing: A qualitative examination of participant experiences. Religion and Health, doi:10.1007/s10943-013-9679-0.

Shonin, E, Van Gordon, W, \& Griffiths, MD. (2013b). Buddhist philosophy for the treatment of problem gambling. Journal of Behavioral Addictions, doi:10.1556/JBA.2.2013.001.

Toneatto, T. (1999). Cogntive psychopathology of problem gambling. Substance Use and Misuse, 34, 1593-1604

Toneatto, T. (2002). A metacognitive therapy for anxiety disorders: Buddhist psychology applied. Cognitive and Behavioral Practice, 9, 72-78.

Toneatto, T, Blitz-miller, T, Calderwood, K, Dragonetti, R, \& Tsanos, A. (1997). Cognitive distortions in heavy gambling. Journal of Gambling Studies, 13, 253-266.

Toneatto, T, Vettese, L, \& Nguyen, L. (2007). The role of mindfulness in the cognitive-behavioral treatment of problem gambling. Journal of Gambling Issues, 19.

Turner, NE. (1998). Doubling vs. constant bets as strategies for gambling. Journal of Gambling Studies, 14, 413-429.

Turner, NE, Annis, HM, \& Sklar, SM. (1997). Measurement of antecedents of drug use and drinking: Psychometric properties of the Inventory of Drug Taking Situations (IDTS). Behaviour Research and Therapy, 35, 465-483.

Turner, N, Littman-Sharp, N, \& Zangeneh, M. (2006). The experience of gambling and its role in problem gambling. International Gambling Studies, 6, 237-266.

Turner, NE, Jain, U, Spence, W, \& Zangeneh, M. (2008). Pathways to pathological gambling: component analysis of variables related to pathological gambling. International Gambling Studies, 8(3), 281-298.

Turner, NE, Littman-Sharp, N, Toneatto, T, Liu, E, \& Ferentzy, P. (2013). Centre for addiction and mental health inventory of gambling situations: evaluation of the factor structure, reliability, and external correlations. International Journal of Mental Health and Addiction, 11(5), 526-545. doi:10.1007/s11469-013-9446-1.

doi:10.1186/2195-3007-4-2

Cite this article as: Chen et al: Mindfulness and problem gambling treatment. Asian Journal of Gambling Issues and Public Health 2014 4:2 